\title{
Chemical Industry in the United States
}

$\mathrm{P}$ ERHAPS the most remarkable thing about the meeting of the American Chemical Society held in April last in New York, and widely heralded as the "Official Tercentenary" of American chemical industry, was the presence of more than 25 per cent of the very large membership, some 17,000, of that Society. No body in Great Britain can count on such loyal support, and it affords a fine illustration of that 'working together' spirit which is carrying the chemical industry forward, so far and so fast, in the United States. Naturally the fare provided was very varied, though by collecting the papers into appropriate groups, it was possible for those with similar interests to forgather.

The social side was well to the fore, a feature being the replacement of elaborate and costly functions by a series of breakfasts, luncheons and dinners, arranged for the alumni of the numerous universities.

The opportunity for propaganda was not missed, including on one hand addresses of a general or topical character delivered by the leaders of the industry, whilst the Press was supplied with a large amount of suitable copy portraying the popular aspect and utility of the work of the chemist. They do these things well in New York under the guidance of the veteran secretary, Mr. Charles L. Parsons, and it is probable that nothing was left undone to make the meeting a gigantic success. It is worthy of comment that all the meetings could be held in the Hotel Pennsylvania, whilst the many delegates could be housed there and in three neighbouring hotels, all connected by underground passages.

Apparently the American chemical leaders are not afraid to criticise the administration. Mr. William B. Bell, president of the American Cyanamide Company, whose theme was "Recovery-by Alchemy or Chemistry", claimed that there is too much Govern. ment planning and too much Government waste; the one sound basis of industrial planning being that of purchase and sale, or profit and loss with no political interference or domination. A director of the Du Pont Company claimed that they are on the way to establish an American synthetic rubber industry, and that this has been made possible by the experience gained in the dye industry, which in particular must be in a position to expand quickly in a national emergency to make a variety of essential organic substances.

Emphasis was also laid on the popular use and significance of vitamins, preparations containing such now having the third largest sale in the drug stores.

As a novelty, it was proclaimed that young cereal grasses cut just prior to jointing have, when dry, a biological value many times that of the common vegetables and that men and women will be eating grass in the near future.

Altogether as wide a range of subjects were discussed as must have been dealt with in that famous conversation between the Walrus and the Carpenter - "and why the sea is boiling hot and whether pigs have wings".

\section{Third International Congress of Soil Science}

$F^{\prime}$ IFTY countries were represented among the four hundred delegates who attended the Third International Congress of Soil Science held in Oxford on July 30-August 7. The occasion afforded an unrivalled opportunity for discussing the many aspects presented by every problem in soil science, but differing widely according to the geographical region in which the problem is studied. One of the most urgent needs of the science is to break down the parochial barriers which necessarily limit the views of workers confined to one climatic or physiographic region, and faced with the whole-time task of economically justifying their existence. That parochialism exists was amply evident at the Congress, as also were the difficulties of overcoming it; but it was equally evident that the holding of an international congress is a practicable means of producing some kind of order among the conflicting theories held by the world's most eminent pedologists.

The discussions brought into prominence several new directions in which this young science is developing. In the Soil Physies Section, the main interest centred round problems of soil moisture, and Dr. R. K. Schofield introduced a ' $p \mathrm{~F}$ ' scale which precisely specifies the degree of wetness or dryness of a soil in much the same way that Sørensen's $p H$ scale specifies the degree of acidity or alkalinity. The $p \mathrm{~F}$ is the (positive) logarithm of the amount by which the free energy of the water in the soil is less than that of water in bulk at the same temperature and external pressure expressed as the height in centimetres of a water column. $1 \mathrm{~cm}$. above a free water table is, therefore, $p \mathrm{~F} 0$ while the 'oven dry' state is approximately $p \mathrm{~F} 7$. The use of this scale enables a great mass of hitherto unrelated data to be welded together to make an orderly picture of aspects of soil moisture behaviour which are of special importance in irrigation. Dr. Schofield stressed the necessity of recognising hysteresis in the relationship of $p \mathrm{~F}$ to moisture content, which he regards as due mainly to microplastic resistance to swelling and shrinking.

In the Chemistry Section much attention was directed, as usual, towards the base-exchange properties of soil colloids, particularly from the mineralogical point of view. The structure of montmorillonite and beidellite, as proposed by Hofman, Endell and Milne, was discussed, and Dr. C. E. Marshall showed that the apparent contradictions between their structure and the chemical formulæ can easily be removed by considering the operation 
of certain replacements, aluminium for silicon in beidellites, and magnesium for aluminium in montmorillonites. Prof. C. H. Edelman proposed an alternative explanation for the base-exchange properties of the clays, having special reference to halloysite, which he regards as having marked exchange properties.

The Soil Fertility Section held a noteworthy discussion on the methods of estimating the manurial requirements of soils. Prof. E. A. Mitscherlich presented the first results of a great co-operative investigation, in which already 120 soils from different parts of the world have been studied, using more than thirty different methods. This investigation is a model of what can be attempted by international co-operation. Prof. O. de Vries surprised his hearers with an account of the number, running into tens of thousands, and the scope of the field experiments which have been made in the Dutch East Indies. Prof. R. A. Fisher followed this practical account by demonstrating the principles upon which the design of field experiments must be based if their results are to be of any real value. He made clear what is often overlooked, that accuracy alone is not enough, unless the degree of accuracy is also known. The very large number of papers dealing with the practical side of soil science which were presented to the Soil Fertility Section emphasised the dominating influence exerted on the development of soil science by modern economic conditions.

This was also apparent in the Soil Classification and Genesis Section. Hitherto the chief object of this section has been to establish an objective basis for soil taxonomy, but the principal matter discussed at Oxford was land rather than soil classification. An excellent series of papers described the methods adopted, with special reference to land settlement plans, in the United States, Canada, Germany and Hungary. Aims and methods differ widely in different countries, and are influenced by modern political trends towards national agricultural planning. The results can scarcely be regarded as objective, but they afford an illustration of the way in which an adolescent science may become involved with a transient political economy. That soil science has become a junior and sometimes fortunately forgotten servant of polities is recognised by research workers striving in many countries to make bricks without straw-to produce the practical results demanded of them with insufficient knowledge of the fundamental nature of the soil. Spectacular successes are still occasionally obtained (though none was described at the Congress) by applying the principles of pure chemistry, physics and biology to soil problems, but the field for such successes is narrowing rapidly, and it seems as if the next real step forward in either pure or applied soil science must be awaited until conditions allow research workers to reason out their problems from the beginning instead of from the end. The general impression left by the Congress was that practice has outstepped theory, and that there is little immediate likelihood that the discrepancy between them will be reduced.

\section{The Radio Exhibition at Olympia}

\begin{abstract}
A VISIT to this year's Radio Exhibition at Olympia, organised by the Radio Manufacturers' Association, gave the impression that the broadcast receiver industry is at last beginning to outgrow its somewhat hectic childhood days, and is settling down to a policy of steady progress and development. On this occasion, the show was conspicuous by the almost complete absence of those 'epoch-making inventions', which in the past have involved the coining of new and wonderful names and the development of complicated valves, in an attempt to improve what has so often been termed 'perfect' reception.
\end{abstract}

The receivers exhibited fall approximately into three fairly distinct classes. The first involves the modest set of three or four stages with straight amplification at radio frequencies, at a price ranging from about five guineas. The second class includes the more elaborate supersonic heterodyne receiver, which combines the advantages of greater sensitivity and selectivity, and which in table and console models can be obtained at prices from ten or eleven guineas upwards. The third involves the incorporation of this receiver into the modern radio-gramophone which, in its more ambitious examples, commands a price ranging from twenty-five to well over a hundred guineas. While all these types of receiver have been available in previous years, the present display showed that the designers and manufacturers are overeoming the difficulties, technical and otherwise, which they have hitherto experienced in the mass- production of a rather complicated piece of radio apparatus. All but the simplest sets now incorporate such features as second-channel suppression, automatic volume control and some device to simplify tuning; while, from the musical listener's point of view, a welcome advance is the incorporation of variable selectivity in the better-class receivers. The general listener is not seriously interested in wavelengths, and to meet this point, it was noticed that there is an increasing tendency on the part of manufacturers to engrave tuning dials with the names of broadcasting stations. While also some firms have made a commendable effort to provide enlarged and improved scales, the indications of which can be read at a glance, in some cases a reminder would appear to be justified to the effect that the ordinary listener is not usually equipped with a pocket magnifying glass. Such a reminder is becoming increasingly necessary now that several receivers are provided with one or two short-wave ranges, in addition to the medium and long-wave ranges. This provision is a welcome addition to this year's sets, and indicates an increased tendency to listen to programmes emanating from stations outside the continent of Europe.

A feature of the exhibition, which is perhaps somewhat significant, was the almost entire absence of any reference to television. One or two firms showed components specially designed for use on ultra-short waves in anticipation of experimenters' requirements, especially when a television service is commenced on 